\title{
Rural Area Development Strategy through Rural Infrastructure Development Program
}

\author{
Suwandi, Wilmina Pesurnay \\ University of cenderawasih Jayapura Papua, Indonesia \\ mndidik7@gmail.com
}

\begin{abstract}
This study was conducted in Biak District of Papua employing the quantitative method. The strategic concept in the development of local institutional capacity was to maximise the role of institutions as social capital not taken over, such as driving as farmers' cooperatives, cooperatives as agro-tourism objects, and integrating the local institutional system under the auspices of Papua local institutions.
\end{abstract}

Keywords: Capacity building, integrated agricultural system (Simantri) system, and sustainable development

\section{Introduction}

The Rural Area Development Concept is developed from the need of a village to improve its function and role in managing the social, economic, cultural and educational life and social welfare in the rural area (Kuntoro, 2006). The influences of globalisation, free markets and regionalisation lead to interstate, inter-regional (city/district), inter-sub-district and inter-village spatial, social, and economic changes and dynamics. Globalisation is also characterised by revolutions in information technology, transportation and management (Syahrani, 2001). The revolutions have caused unclear boundaries of urban and rural areas, polarisation of regional development, formation of global cities, international-scale city systems, formation of trans-border regions and establishment of regional development either corridors for the local national, regional and international scales. Spatial-based planning plays an important role in formulating development policies (Supriatna, 2000). Therefore, spatial development of villages is part of regional development of sub-districts and districts, in which the preparation of sub-urban development plan needs to begin with an analysis of conditions, potentials and problems of a region to determine the causality of socio-economic developments, potential natural resources, human capacity, regional infrastructure and regional development objectives (Adisasmita, 2005). The sub-urban spatial planning aims at directing spatial structure, location and functional relationships of a village in a harmonious, balanced and aligned manner in order to utilise potential natural resources and technologies so as to achieve optimum results of rural development for quality improvements of human life and the environment in a sustainable manner.

\section{Literature Review}

Sub-urban Planning Concepts: The sub-urban development plan is a guide or model for sub-urban potential exploration and development ideas focusing on community participation in the overall development process. The concept is based on the values and spirit of mutual cooperation that has been rooted in the Indonesian culture (Anonymous, 2007). Mutual cooperation is based on the belief that every citizen has the right to decide and plan what is best for him/her and the environment and the best way in an effort to make it happen. Broadly speaking, the sub-urban planning implies the following (Sumodiningrat, 2000);

a. Planning as a series of analysis activities from identification of needs to determination of community development program.

b. Environmental development planning; all programs to improve welfare, tranquillity, prosperity and peace of communities in residential neighbourhoods from RT/RW, hamlets to villages.

c. Development planning relies on problems, needs, aspirations and resources of local communities.

d. Sub-urban planning is a tangible manifestation of community participation in future development.

e. Planning to produce development programs which are expected to have an impact on improving welfare, prosperity and peace for a long run. 
Development Policies and Programs in Rural Areas: A rural area covers smaller areas with certain conditions and functions that are different from each other (Anonymous, 2004; 2007). Inter-regional development of an area will differ, depending on potential natural resources, human resources, and socioeconomic-cultural conditions of a community living therein (Salim, 2006). A rural area has potentials and conditions that support development, thus will be more prominent in terms of growth and development as compared to other areas (Supriatna, 2000; Syahrani, 2001). It is called a 'potential area' or a 'rural strategic area'. A potential area or a strategic area of medium-term development as stated in the National MediumTerm Development Plan (RPJMN) 2004-2009 (Presidential Decree No. 7/2005) includes: (a) creating a safe and peaceful Indonesia, (b) creating a fair and democratic Indonesia, and (c) improving welfare of the people. The development Priorities and policy directions are: poverty reduction and unemployment reduction, investment increase, revitalisation of agriculture, fisheries and forestry, rural development and reduction of inter-region imbalances, improvement of people's access to quality education and healthcare, increase in social protection and welfare, development of quality population, and acceleration of infrastructure development (Indrawati, 2005).

Based on various research and reviews of agricultural development policies, agriculture revitalisation through agro-industry development in rural areas is a strategic choice to drive the wheels of economy and the empowerment of rural community economy (Aziz, 2008). This is possible because of the high ability of agroindustry in employment, given that the agricultural industry is labour-intensive and massive in nature (Efiawan, 2004; Kuntoro, 2006). The middle- and lower-class community-based agricultural industry is a sector that is suitable for accommodating a lot of manpower and ensuring the expansion of doing business, thus, being effective in improving the economy of rural areas (Anonymous, 2005). The effort to revitalise the agricultural sector in Indonesia is the second-round green revolution in Indonesia (Nainggolan, 2008).

\section{Methodology}

This research is quantitative, which aimed at determining an overview of people with regard to rural development. The research variables were five, namely: upstream sub-systems (seed procurement, fertilizer and pesticide procurement, agricultural equipment and machinery procurement), farming sub-systems (tillage, seeding, planting, maintenance, and harvesting, farming environment), and processing sub-systems (product collection, packing, processing), marketing sub-systems (product distribution, marketing) and supporting and service sub-systems (capitalisation, education and training, social activities). Total attributes of these five variables being analysed were 17. 70 respondents were examined under the research, those being spread over five villages with agricultural advantages. The data analysis employed the exploratory factor analysis (EFA) with SPSS version 20 software. The factor analysis could be used when interdependence of all attributes was acceptable, in which Kaiser-Myer-Olkin (KMO) had a value more than 0.50. EFA would generate a number of new factors consisting of several attributes to describe the total diversity. Extraction of factors would be optimised by selecting a varimax rotation so as to generate a higher loading factor for each attribute.

\section{Results}

The calculation result of KMO value of 0.703 explained that the interdependence of all attributes was acceptable. Extraction of EFA produced 17 components, but only 5 components were used. The number of components to be used was the number of components with eigen values over 1 . The contributions of the first, second to fifth component were $27.151 \%, 16.750 \%, 11.624 \%, 7.757 \%$ and $7.225 \%$, respectively, in explaining the total diversity, thus cumulatively being $70.706 \%$. Extraction of the first component consisted of six attributes to be named by processing and marketing factors: packing, product distribution, product collection, marketing and social activities. The first component explained that processing and marketing issues were important issues as in many regions there was a quite wide gap on the ability of people with regard to both issues. The second component would be named by seed and planting technique factors, consisting of attributes: seeding, planting and seed procurement. The right method of planting would take part in determining yields, in addition to the support of good seed quality. The third component was farm factors, consisting of attributes: harvesting, capitalisation (finance), maintenance and education and training. Crop harvesting and maintenance techniques needed to be known accurately through farming education and 
training opportunities. Rural communities with the major commodities in agriculture should also be able to calculate capital requirement in farming undertaken. The fourth component was named by upstream factors, consisting of: fertilizer and pesticide procurement, tillage and equipment and machinery procurement. The fifth component was named by irrigation environment, consisting of: farming irrigation and environment.

Table 1: Summary of Results of Exploratory Factor Analysis

\begin{tabular}{|c|c|c|c|c|c|c|}
\hline \multirow[t]{2}{*}{ Description } & \multirow[t]{2}{*}{ Label } & \multicolumn{5}{|c|}{ Component } \\
\hline & & 1 & 2 & 3 & 4 & 5 \\
\hline Packing & КЕРАК & 0.862 & -0.047 & -0.071 & -0.053 & 0.044 \\
\hline Product distribution & DISTRIBUSI & 0.843 & 0.100 & -0.156 & -0.112 & 0.109 \\
\hline Product collection & KUMPUL & 0.783 & 0.213 & -0.011 & 0.023 & -0.184 \\
\hline Marketing & PASAR & 0.638 & 0.010 & 0.257 & 0.206 & 0.174 \\
\hline Social activities & SOSIAL & 0.575 & 0.118 & 0.289 & 0.290 & 0.367 \\
\hline Seeding & BIBIT & 0.148 & 0.900 & 0.137 & 0.130 & 0.112 \\
\hline Planting & TANAM & 0.044 & 0.891 & 0.210 & 0.019 & 0.032 \\
\hline Seed procurement & BENIH & 0.079 & 0.780 & -0.227 & 0.135 & 0.188 \\
\hline Harvesting & PANEN & 0.218 & 0.033 & 0.782 & 0.010 & 0.002 \\
\hline Capitalisation/ Finance & MODAL & -0.145 & -0.135 & 0.674 & 0.047 & 0.172 \\
\hline Maintenance & PELIHARA & 0.111 & 0.289 & 0.646 & 0.379 & 0.081 \\
\hline Education \& Training & DIKLAT & -0.214 & 0.274 & 0.580 & 0.221 & 0.354 \\
\hline $\begin{array}{l}\text { Fertilizer and pesticide } \\
\text { procurement }\end{array}$ & PUPUK & 0.040 & -0.031 & 0.126 & 0.813 & 0.278 \\
\hline Tillage & TANAH & 0.082 & 0.294 & -0.067 & 0.790 & 0.039 \\
\hline Equipment procurement & ALAT & -0.072 & 0.029 & 0.458 & 0.755 & -0.046 \\
\hline Irrigation & AIR & 0.022 & 0.061 & 0.058 & 0.130 & 0.851 \\
\hline Farming environment & USAHA & 0.169 & 0.210 & 0.206 & 0.053 & 0.722 \\
\hline Eigenvalue & & 4.616 & 2.847 & 1.976 & 1.319 & 1.228 \\
\hline$\%$ Total Variant & & 27.151 & 16.750 & 11.624 & 7.757 & 7.225 \\
\hline \% Cumulative Variant & & 27.171 & 43.900 & 55.524 & 63.281 & 70.706 \\
\hline
\end{tabular}

KMO = 0.703; Non-redundant residual more than $0.05=38 \%$

The effort of rural area development was intended to improve the general condition as productive economic areas and relatively underdeveloped settlements compared to those of urban areas. In the future, it was expected that obstacles and challenges as those in previous years would be encountered, including: (a) lack of coordination and integration of activities among development stakeholders (among the government, the public, and the private sector) and among sectors in order to encourage diversification of economic activities of rural areas (Adisasmita, 2005) that strengthen the linkages among agricultural sector (on-farm), industry, and supporting services (off-farm), as well as the spatial linkages between rural areas and urban areas; (B) lack of the roles of institutions and organisations including rural community development facilitators in driving the economy in rural areas; (C) lack of capacity and independence of local governments in promoting local economic development and rural community empowerment under their authorities; and (d) high demands for provision of quality infrastructure in rural areas evenly across the country.

\section{Conclusion}

In order to encourage integrative agriculture from upstream to downstream in the future, there must be an economic incentive for the realization of potentials in rural areas which have not been utilised optimally, taking into account the balance of the ecosystem. A series of policies must be designed in the transformation process, including: (a) empowerment of the poor in rural areas and organisational/ institutional 
strengthening; (b) improving access to resources (such as land, water, and forests) and technologies; (c) preserving and fostering technologies and local cultures; (d) the importance of education of rural communities and food security; (e) improving access to capital and markets; (f) fiscal stimulus to boost agricultural growth; (g) enhancing the roles and functions of universities as a source of pure and applied science and technology development. Rural area development also needs the increasing roles and functions of institutions in rural community development. The village administration should continue to foster the spirit of community initiation, self-reliance and mutual cooperation. Improving governance of community and village empowerment has always been one of the major programs in rural infrastructure development.

\section{References}

Adisasmita, H. R. (2005). Fundamentals of Economic Region. Publisher Graha Science, Yogyakarta.

Anonymous. (2004). Basic Concepts Development Agropolitan. Jakarta: Director General Depkimpraswil Tata Tata Urban and Rural.

Anonymous. (2005). Presidential Decree Number 7 of 2005 on the National Medium Term Development Plan (RPJMN) 2004-2009. Jakarta: State Secretariat.

Anonymous. (2007). Rural Development. Jakarta: Ministry of Public Works, August 2007).

Aziz, B. (2008). Preparation of Countryside Development Program Growth Centre (DPP Torue) District. Parigi Moutong Independent Research Report. Palu: Department of Architecture UNTAD.

Efiawan, H. R. (2004). Regional Management As Alternative Approaches to Inter-regional Development Management in the Era of Decentralization. Papers in Regional Day Seminar in the Perspective of Regional Autonomy and Regional Development, Semarang.

Indrawati, S. M. (2005). Progress Report on the MDGs (Millennium Development Goals / MDGs) Country Indonesia Year 2005.

Kuntoro, B. A. (2006). Perspective Rural Regional Development, Innovation Magazine Vol. 6 / XVIII / March 2006, at PPI Online Website.

Nainggolan, K. (2008). Against Hunger and Poverty Century 21 First edition May). Bogor: Eternal Press.

Salim, F. (2006). Urbanization, Rural-City, Growth Centre. Bandung: Institute for Public Policy Observer Univ. Padjadjaran.

Sumodiningrat, G. (2000). Economic Development Development Through Agriculture, PT.BINA Rena Tourism, Jakarta.

Supriatna, T. (2000). Development Strategy and Poverty. Publisher Rineka Cipta, Jakarta.

Syahrani H. H. A. (2001). Implementation Agropolitan and Agribusiness In Regional Economic Development. Frontier Journal, 33(2). 